\title{
Referencing geostrophic velocities using ADCP data at $24.5^{\circ} \mathrm{N}$ (North Atlantic)
}

\author{
ISIS COMAS-RODRÍGUEZ ${ }^{1}$, ALONSO HERNÁNDEZ-GUERRA ${ }^{1}$ and \\ ELAINE L. MCDONAGH ${ }^{2}$ \\ ${ }^{1}$ Facultad de Ciencias de Mar, Universidad de Las Palmas de Gran Canaria, Campus Universitario de Tafira, 35017, \\ Las Palmas, Spain. E-mail: isis.comas102@doctorandos.ulpgc.es \\ ${ }^{2}$ National Oceanography Centre, Southampton, University of Southampton Waterfront Campus, European Way, \\ Southampton SO14 3ZH, United Kingdom.
}

\begin{abstract}
SUMMARY: Acoustic Doppler Current Profilers (ADCPs) have proven to be a useful oceanographic tool in the study of ocean dynamics. Data from D279, a transatlantic hydrographic cruise carried out in spring 2004 along $24.5^{\circ} \mathrm{N}$, were processed, and lowered ADCP (LADCP) bottom track data were used to assess the choice of reference velocity for geostrophic calculations. The reference velocities from different combinations of ADCP data were compared to one another and a reference velocity was chosen based on the LADCP data. The barotropic tidal component was subtracted to provide a final reference velocity estimated by LADCP data. The results of the velocity fields are also shown. Further studies involving inverse solutions will include the reference velocity calculated here.
\end{abstract}

Keywords: ADCP data, CTD data, reference velocity, geostrophic velocity, velocity correction, North Atlantic Ocean.

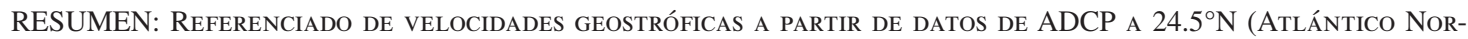
TE). - Los perfiladores de corriente acústicos Doppler (Acoustic Doppler Current Profiler - ADCPs) son una herramienta oceanográfica útil en el estudio de la dinámica oceánica. Se han procesado los datos de la sección transatlántica a lo largo de $24.5^{\circ} \mathrm{N}$, realizada durante la campaña oceanográfica D279 en primavera de 2004 , mientras que los datos de "bottom track" del LADCP (Lowered ADCP) se han empleado en la elección de la velocidad de referencia aplicada a los cálculos geostróficos. Se realizan comparaciones entre los datos obtenidos mediante diferentes combinaciones de ADCP's. Finalmente, se obtiene una velocidad de referencia final mediante las medidas de LADCP, a las que se resta la componente barotrópica de la marea. Asimismo, se muestran los campos de velocidad resultantes. Estudios futuros incluirán la velocidad de referencia calculada en la obtención de resultados mediante modelos inversos.

Palabras clave: datos de ADCP, datos de CTD, velocidad de referencia, velocidad geostrófica, corrección de velocidades, océano Atlántico norte.

\section{INTRODUCTION}

Velocity observations from Acoustic Doppler Current Profilers (ADCP's) provide an oceanographic tool for studying many aspects of ocean dynamics. Ship-mounted ADCPs (SADCPs) give detailed insights into upper-ocean dynamics to a maximum depth of approximately $1000 \mathrm{~m}$. Lowered ADCPs (LADCPs) provide velocity profiles over the full range of depths of standard hydrographic casts.

Direct velocity measurements have already been used to study oceanic circulation. Direct velocity measurements of the Agulhas Current from an LAD$\mathrm{CP}$ revealed a very different vertical structure than that given by the traditional assumption of a zero velocity surface in a deep and horizontal layer. The total volume transport of the Agulhas Current was 
re-estimated, and the presence of a north-eastward undercurrent was revealed (Beal and Bryden, 1997). LADCP data have also been used to correct the initial geostrophic calculations in different oceanographic regions (Joyce et al., 2001; McDonagh et al., 2008). In these two cases, the velocity observations were used to correct the choice of reference velocity for the initial geostrophic field of an inverse model.

The main scientific objective during cruise 279 carried out in spring 2004 onboard the RRS Discovery (D279) was to estimate the circulation across the zonal section at $24.5^{\circ} \mathrm{N}$ in the $\mathrm{N}$ Atlantic Ocean. This section has been studied previously in 1957 (Fuglister, 1960), 1981 (Roemmich and Wunsch, 1985), 1992 (Parrilla et al., 1994) and 1998 (Baringer and Molinari, 1999). Cruise D279 in 2004 included, for the first time for this section, LADCP profiles that can be used to provide the reference velocity and as constraints in an inverse study.

Circulation across $24.5^{\circ} \mathrm{N}$ and its variability has already been studied using cruise D279 data. These estimates are limited by the uncertainty concerning the reference velocities, estimated as zero near 1000 dbar between $80^{\circ} \mathrm{W}$ and $70^{\circ} \mathrm{W}$ and near $3000 \mathrm{dbar}$ for the rest of the section. A uniform reference level velocity has also been added to force the mid-ocean geostrophic transport to balance the Gulf Stream plus Ekman transport (Bryden et al., 2005). Our study aims to apply a LADCP-referenced depth-averaged offset to each geostrophic profile. These reference velocities will be used to correct the geostrophic velocities.

The results of this work will be used in another study which will compare the circulations from an inverse solution with an initial field prescribed by ADCP data (reference velocities derived here) and one initialized using a traditional zero reference velocity. The circulation at $24.5^{\circ} \mathrm{N}$ and the section property distributions will provide heat, freshwater and other property fluxes. The size and structure of the Atlantic Meridional Overturning Circulation (AMOC) will be calculated and compared to results using the transatlantic mooring array deployed in the framework of the rapid climate change/meridional overturning circulation and heat flux array (RAPID/ MOCHA) experiment (Cunningham et al., 2007; Kanzow et al., 2007).

\section{MATERIAL AND METHODS}

\section{Data acquisition}

Cruise D279 onboard the RSS Discovery occupied a transatlantic section at a nominal latitude of $24.5^{\circ} \mathrm{N}$ (Fig. 1). It took place in spring 2004 (4 April to 10 May), and took full-depth hydrographic, velocity and chemistry measurements from shallow waters on the eastern seaboard of the USA to shallow waters near Africa (Cunningham, 2005). During the cruise, 125 full depth CTD (Seabird 911+) stations were carried out with dual sensors. CTD conductivities were calibrated by comparing them to bottle conductivities derived from water samples obtained during the CTD upcast. A slope correction was applied to account for sensor drifts.

Three Lowered Acoustic Doppler Current Profilers (LADCPs) were mounted on the rosette and deployed at each CTD cast. Continuous observations were made in the upper $1000 \mathrm{~m}$ using a shipboard ADCP (SADCP) installed on the research vessel's hull. The LADCPs consisted in one Broadband (BB) $150 \mathrm{kHz}$ running free in downward looking mode, with its own battery pack, and two $300 \mathrm{kHz}$ Workhorse (WH) narrow band units, which were run in master/slave mode, one upward looking (slave) and one downward looking (master) with a shared battery pack. The SADCP installed was an Ocean Surveyor $75 \mathrm{kHz}$ with a narrow band phased array

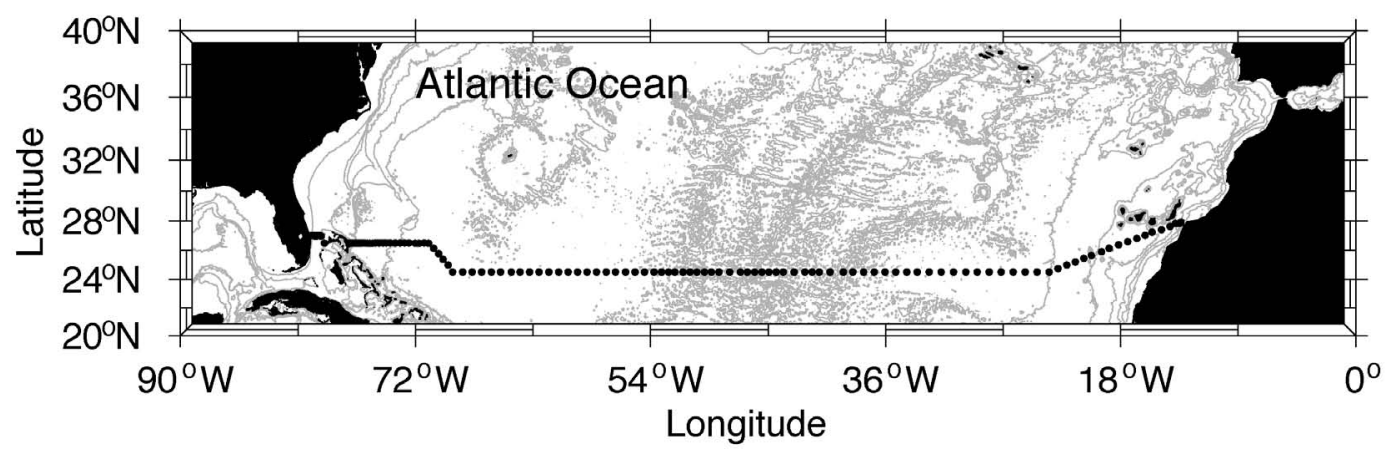

FIG. 1. - Station positions for the transatlantic hydrographic section occupied during cruise D279. 125 full depth stations were used along a nominal latitude of $24.5^{\circ} \mathrm{N}$. 


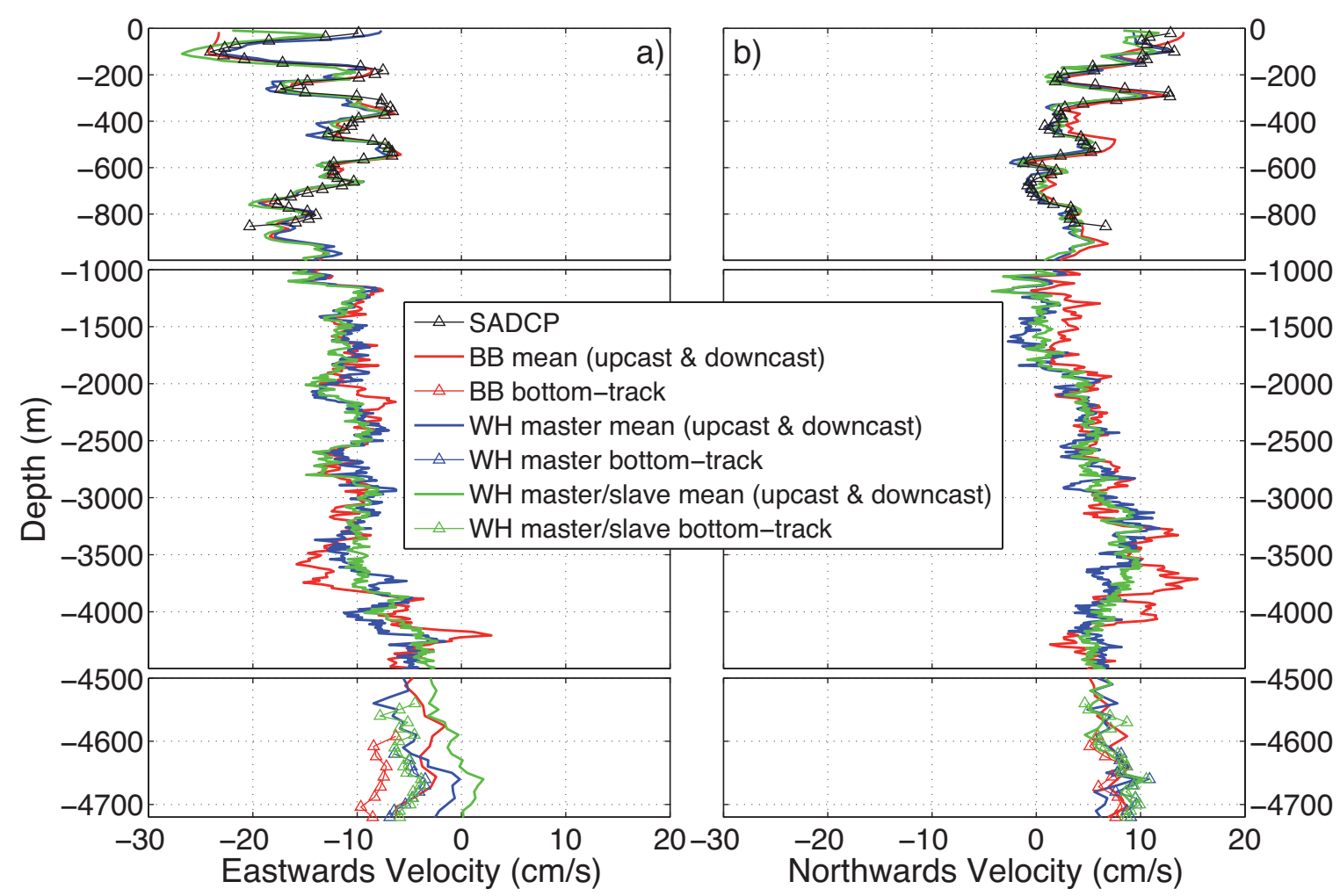

FIG. 2. - LADCP data processed using the Visbeck method at Station $\# 23\left(26.5^{\circ} \mathrm{N}, 75.9^{\circ} \mathrm{W}\right)$ : a) eastwards velocity component, b) northwards velocity component. BB and WH master represent data processed individually, while $\mathrm{WH}$ master/slave corresponds to the combined data of the down- and up-looking WH running in master/slave mode. Note that the vertical scale is different for each depth range. Mean profiles are the average of the upcast and downcast.

with a 30-degree beam angle. It was configured to take samples at 120 second intervals, with 60 bins of $16 \mathrm{~m}$ thickness, and a blank beyond transmit of $8 \mathrm{~m}$. Data were logged using RDI (Teledyne RD Instruments) data acquisition software and were averaged into 2 minute and 10 minute averaged files. The former were then used for SADCP data processing.

\section{LADCP data processing}

LADCP data were processed with the Visbeck software, developed in the Columbia University (Fischer and Visbeck, 1993). The procedure was carried out using LADCP data in different combinations in order to determine which full depth profiler took the best measurements during the cruise.

Three combinations of LADCP data were processed with the Visbeck software: data from the BB, the WH master, and the WH master/slave pair. A GPS reference was applied to calculate the absolute velocity. The options in the software for referencing the bottom-track data or the SADCP data (Visbeck, 2002) were not used; rather, we kept the bottom-track ADCP and SADCP data as independent information to compare them with the processed LADCP data.

Figure 2 shows the processed data for each instrument combination at Station $\# 23\left(26.5^{\circ} \mathrm{N}, 75.9^{\circ} \mathrm{W}\right)$. Bottom track data are also shown for comparison in the depth range near the sea bottom, and SADCP data are shown in the upper $1000 \mathrm{~m}$. Discrepancies are particularly apparent between the bottom track profiles and the LADCP measurements near the bottom. According to the processing software, the average error estimated is $1.8 \mathrm{~cm} \mathrm{~s}^{-1}$ for Station \#23 bottom track data. Initially, bottom track data were considered the best estimate for velocity corrections, and this station used as representative of the main transect; however, a statistical study is needed in order to quantify these differences and determine which instrument performed better during the cruise. Close to zero differences between the BB and the downlooking WH bottom track measurements at each station would imply better data quality (Fig. 3a).

Each full depth profile was compared to its instrument bottom-track, and the downcast, upcast and the mean obtained from both were considered separately. $\mathrm{BB}, \mathrm{WH}$ master and the $\mathrm{WH}$ master/slave package were processed independently. The measurements 


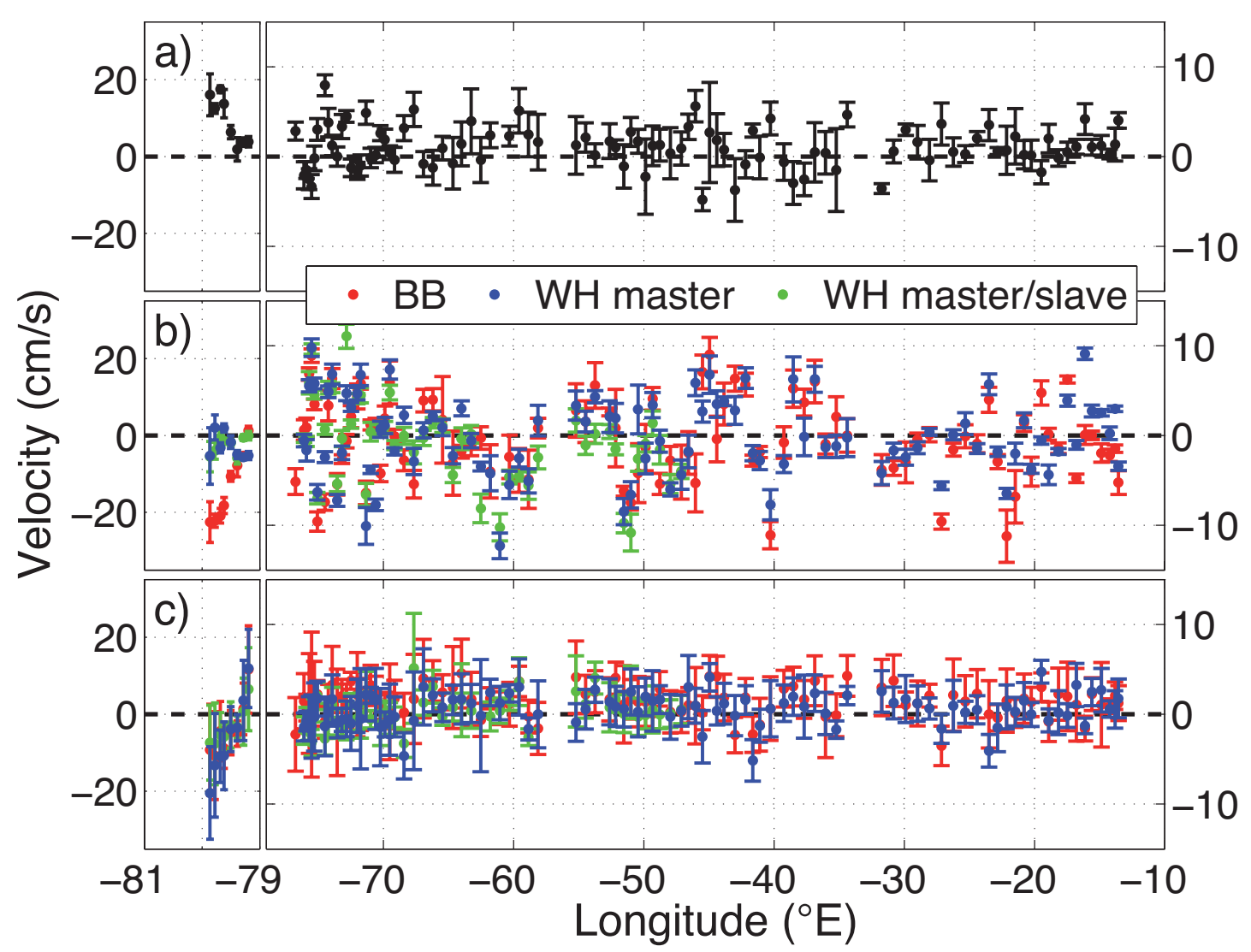

FIG. 3. - Statistical analysis carried out for the three different instruments deployed during the survey: a) mean and standard deviation of the differences between the BB and WH master bottom track measurements; b) mean and standard deviation of the differences between each LADCP full depth profile and their bottom track record in the depth range near the sea bottom; c) mean and standard deviation between each LADCP full depth profile and the SADCP profile in a depth range near the sea surface.

near the bottom were compared to the bottom-track data in the matching depth range (Fig. 3b). We assume that LADCP measurements that are close to the bottom-track data are of better quality, that is, they have closer to zero difference values. SADCP data were also compared to the profile values near the surface in the coincident depths (Fig. 3c). Means and standard deviations to each offset were obtained. The instrument that performed better is the one whose mean differences and deviation are the closest to zero. To determine these differences, the western boundary and the ocean interior were considered separately due to their different dynamics. Two values are shown below, the first one corresponds to the western boundary and the second one to the ocean interior. Averaging each instrument's performance during the cruise, the difference obtained between the $\mathrm{BB}$ and WH master bottom track measurements is $8.8 \pm 0.1 / 1.0 \pm 0.2 \mathrm{~cm} \mathrm{~s}^{-1}$ (Fig. 3a). However, the mean differences between each instrument and its bottom track are $-12.5 \pm 0.1 /-0.2 \pm 0.2 \mathrm{~cm} \mathrm{~s}^{-1}$ for the BB, $-3.1 \pm 0.1 /-0.1 \pm 0.1 \mathrm{~cm} \mathrm{~s}^{-1}$ for the WH master processed individually, and $-2.6 \pm 0.0 /-0.7 \pm 0.1 \mathrm{~cm} \mathrm{~s}^{-1}$ for the WH master/slave combination (Fig. 3b). Finally, the mean differences calculated for each LADCP in comparison with the SADCP data are $-3.7 \pm 0.1 /$ $1.3 \pm 0.3 \mathrm{~cm} \mathrm{~s}^{-1}$ for the BB, $5.9 \pm 0.2 / 0.4 \pm 0.2 \mathrm{~cm} \mathrm{~s}^{-1}$ for the WH master processed individually and $-3.1 \pm 0.2$ / $-1.2 \pm 0.2 \mathrm{~cm} \mathrm{~s}^{-1}$ for the WH master/slave combination (Fig. 3c).

Considering that the mean difference is smaller for the WH master, we have chosen this instrument for the correction of the geostrophic velocities, processed individually without the WH slave data. We are assuming here that $\mathrm{WH}$ master data are better quality because the measurements are closer to the bottom-track data and SADCP data than the other instruments. This is mostly seen in the ocean interior, while the WH master/slave combination provides better results on the western boundary. Unfortunately, a study using the WH in master/slave mode is not possible due to the fact that the uplooking WH (slave) underwent some data reception errors during the cruise and was therefore not used after Station $\# 81\left(24.5^{\circ} \mathrm{N}, 44.9^{\circ} \mathrm{W}\right)$ near the eastern end of the survey. 
Only the velocity component that is perpendicular to the section is considered further. Thus, a velocity rotation was applied in the non-zonal parts of the section, near the eastern and western boundaries.

\section{Tidal barotropic component correction}

The barotropic tidal component was subtracted from the LADCP, bottom-track and SADCP velocity measurements. It was calculated using the OSU (Oregon State University) TOPEX/POSEIDON global tidal model (TPXO) (Egbert et al., 1994; Egbert and Erofeeva, 2002). This global model of ocean tides best fits, in a least-squares sense, the Laplace Tidal Equations and along track averaged data from TOPEX/POSEIDON and Jason (on TOPEX/POSEIDON tracks since 2002) obtained with OTIS (OSU Tidal Inversion Software). The time considered for the tidal prediction is the bottom track time, which is half way through the time spent at the station.

Once calculated, the tidal barotropic component (Fig. 4) was subtracted from the velocity measurements taken by the LADCP, including bottom-track measurements and SADCP profiles.

\section{Reference velocity field}

The initial geostrophic velocity field was calculated with a zero-velocity reference layer at $1000 \mathrm{~m}$ at Stations $\# 1-44\left(79^{\circ} \mathrm{W}\right.$ to $\left.69.5^{\circ} \mathrm{W}\right)$ and $3000 \mathrm{~m}$ at Stations \#45-125 $\left(69.1^{\circ} \mathrm{W}\right.$ to $\left.13.4^{\circ} \mathrm{W}\right)$ following the study carried out by Bryden et al. (2005). When the deepest common depth was less than the reference level (e.g. near the eastern boundary), the bottom was considered as the zero velocity layer. As already mentioned, the reference velocity was obtained using WH master bottom-track data. Each station pair has a geostrophic velocity profile and two bottom track data profiles located on the two stations surrounding it. Therefore, the correction was applied calculating differences between geostrophic and bottom-track profiles at the corresponding depth range. The differences obtained were averaged and a final mean of the contributions of the stations on either side was used (Fig. 5). Therefore, a comparison can be made between each station pair's geostrophic profile and the LADCP data, by considering this reference velocity derived from the mean of the LADCP measurements from the stations on either side. In station pairs with LADCP data only available for one station, this is taken as the whole correction contribution.

\section{RESULTS}

The initial geostrophic velocity profile (referenced to 1000 dbar) and those using the LADCP information were compared as shown in Figure 5, which corresponds to the station pair \#22-23 (located at $26.5^{\circ} \mathrm{N}$, at $76.1^{\circ} \mathrm{W}$ and $75.9^{\circ} \mathrm{W}$ respectively). Individual plots, as shown in Figure 5, were drawn to compare the initial velocity profile at each station pair with the ADCP-referenced, as well as the bottom track data taken into account for each correction, corresponding to the data from the previous and following station. SADCP was also included in these plots in order to check the resemblances between the available data and the corrections made. A slight disagreement between them can be seen due to the fact that measurements at the bottom were used as the reference in the correction. As this was applied to the whole water column, there are reasonable differences considering there is high ageostrophic behaviour at the surface.

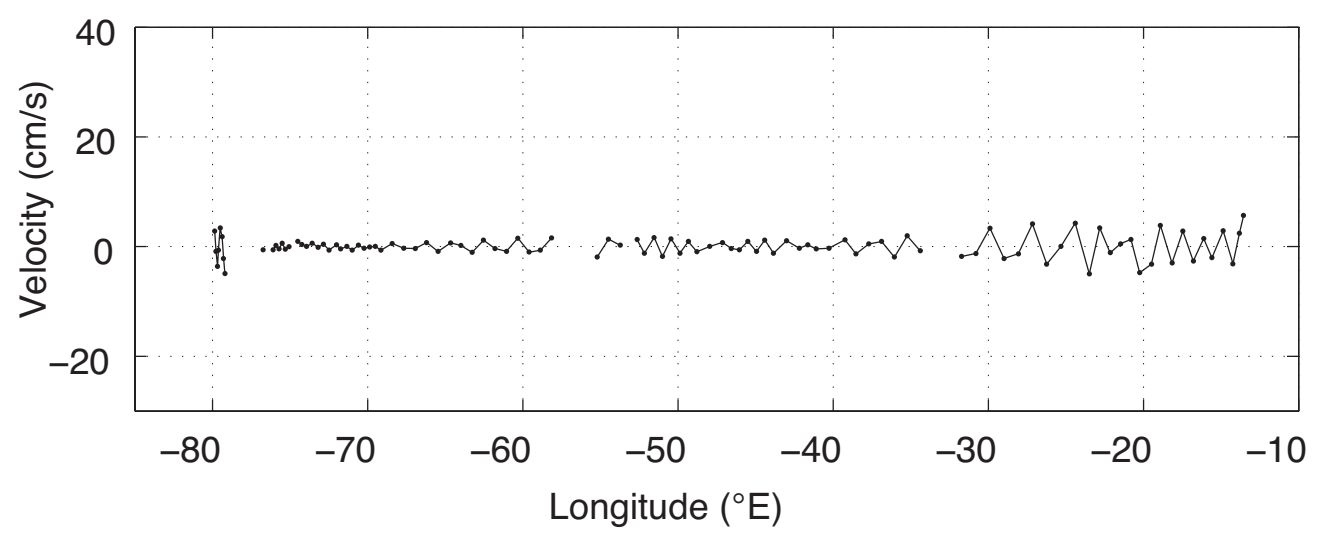

FIG. 4. - Tidal barotropic component calculated from the OSU TPXO tide prediction model. This velocity is subtracted from the velocity measurements of the LADCP and SADCP profiles. 


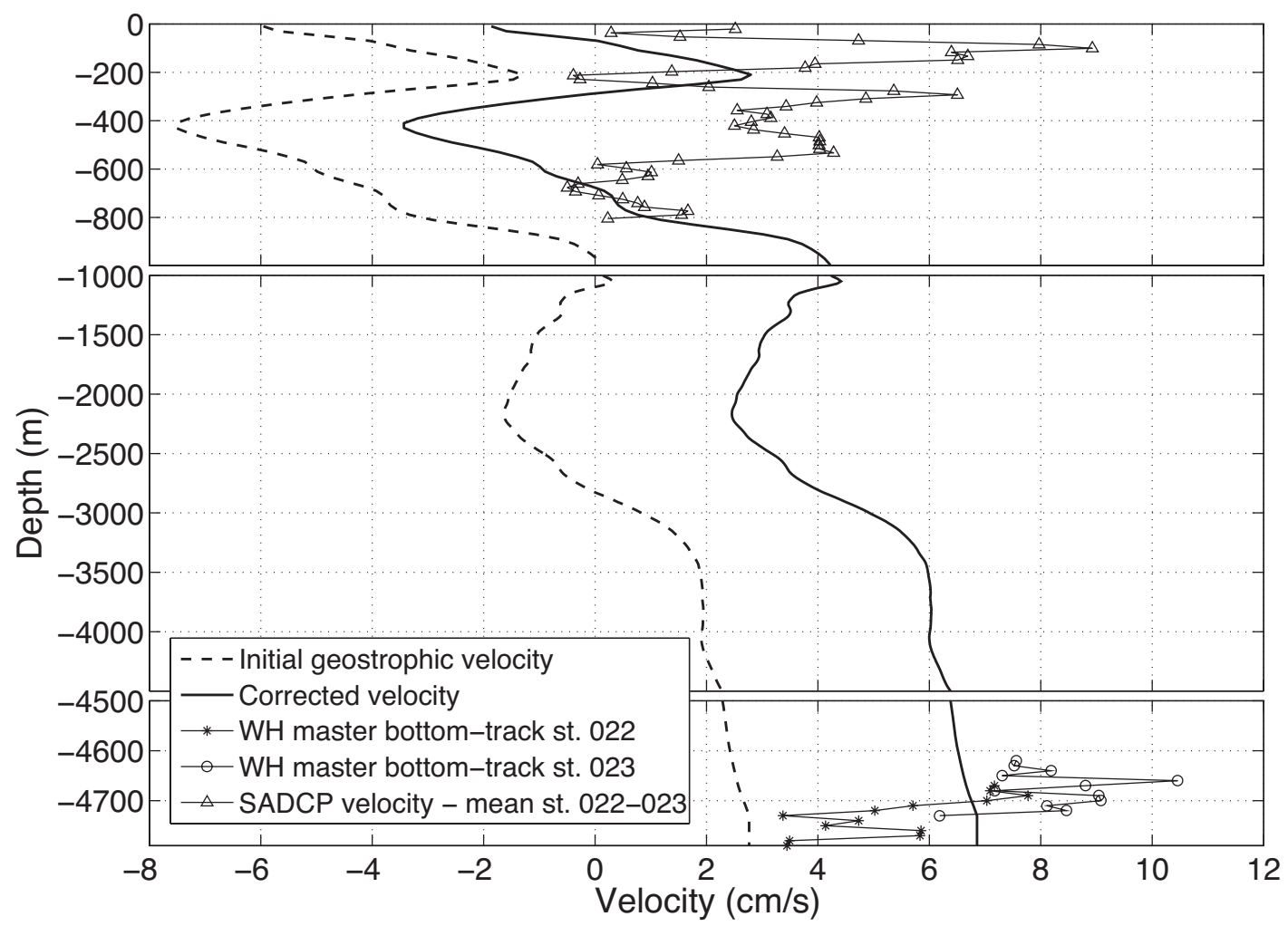

FIG. 5. - Comparison between the initial geostrophic profile and the ADCP-referenced for station pair \#22-23 (located at $26.5^{\circ} \mathrm{N}$, at $76.1^{\circ} \mathrm{W}$ and $75.9^{\circ} \mathrm{W}$ respectively). The dashed line represents the initial calculation while the solid one is corrected using ADCP data. Red and blue triangles correspond to bottom track records of Stations 22 and 23 respectively. Green triangles show the SADCP velocity calculated as the mean of the measurements taken during each cast. Note that the vertical scale is different for each depth range.
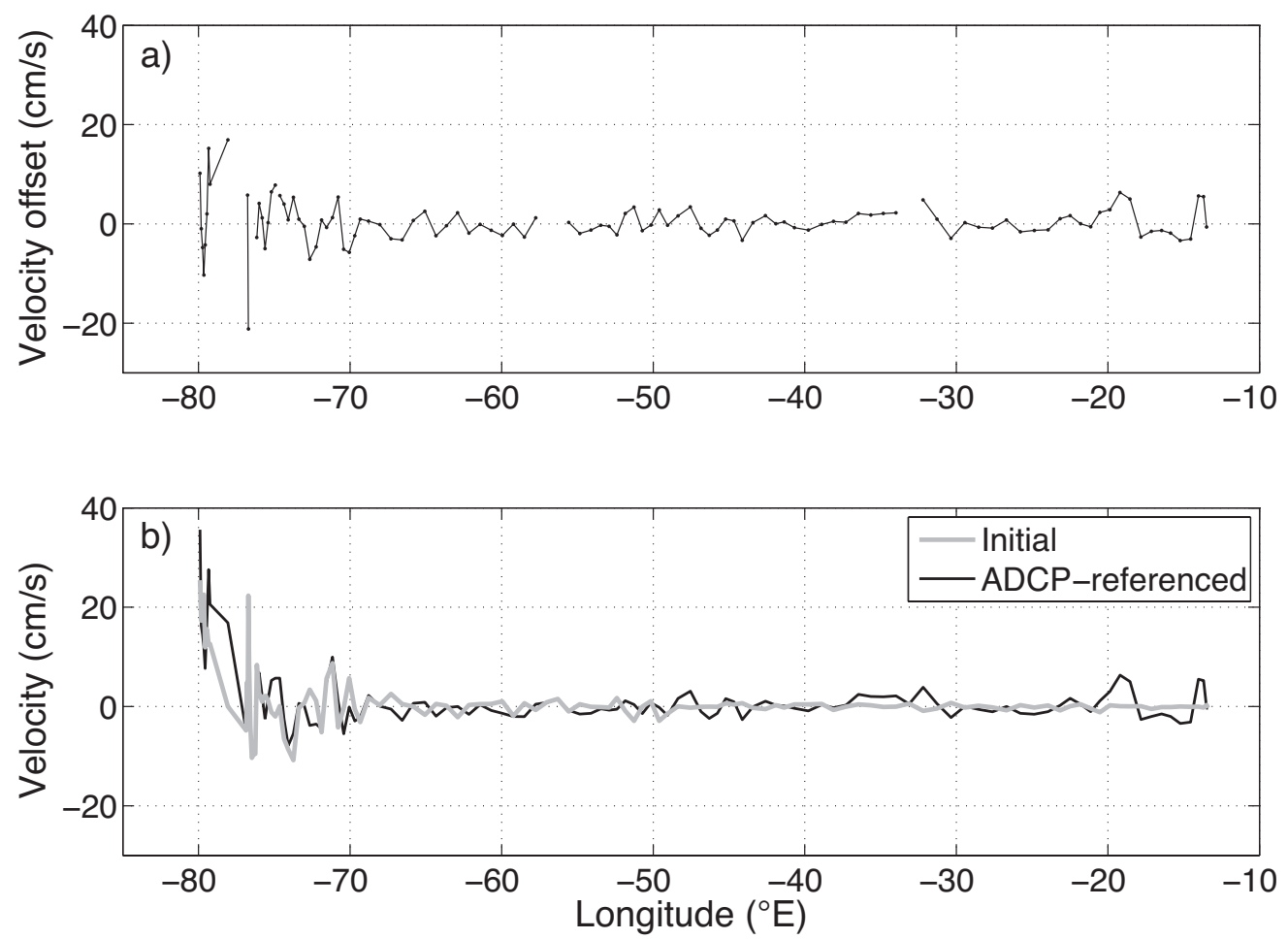

FIG. 6. - a) velocity obtained from the depth-averaged offset of each geostrophic profile, considered as the reference velocity providing the new corrected calculations; b) final velocity estimated at the sea bottom before (grey line) and after (black line) the referencing ADCP data contribution was taken into account. 
SADCP data can be included in the study in two ways: firstly, by taking the value for each station pair as the averaged measurements during each cast, and secondly, by taking the values obtained while the ship sailed between stations and averaging them. In both cases, ageostrophic features are included in the data. Thus, the first option was chosen so as not to include the possible ageostrophic features located between stations registered while sailing, but those registered on the station's position.

The reference velocity was plotted for each station pair throughout the section to examine the corrections made (Fig. 6a). As already mentioned, the initial reference velocity was considered to be zero in the geostrophic calculations (Bryden et al., 2005). In Figure 6a, the reference velocity shown reflects the behaviour of some oceanographic features. On the western boundary, high positive (northward) velocities across the section represent the contribution of the Florida Current at approximately $80^{\circ} \mathrm{W}$. Moving eastwards, negative (southward) velocities represent a recirculation structure and the Deep Western Boundary Current (DWBC) located near $77^{\circ} \mathrm{W}$. Moving further eastwards, some minor structures are present with offsets of less than $5 \mathrm{~cm} \mathrm{~s}^{-1}$. The positive and negative veloci- ties switching between adjacent groups of stations represent the mesoscale contribution. The LADCP provided reference level velocities. To visualize them, final velocity estimations at the sea bottom at each station pair were plotted for the initial case considering zero reference velocity and for the LADCP-referenced velocity field (Fig. 6b). The contribution of the LADCP data can be clearly seen (black line). Figure 7 shows vertical sections highlighting the structure of the velocity field across the section before and after the correction. As expected, no qualitative changes are apparent near the surface, where alternating northward and southward flows are a feature of each velocity field. The differences between the two velocity fields are most apparent near the original zero reference velocity level. Almost-barotropic currents are clearly seen along the section including the northward/southward adjacent currents that represent the eddy oceanic field. The same final velocity field would be obtained when LADCP-referenced velocities are obtained, regardless of the initial reference layer proposed for the geostrophic calculations. The reference velocity provided by the bottom track data would change in order to adjust the different initial velocity profiles to the LADCP measurements.
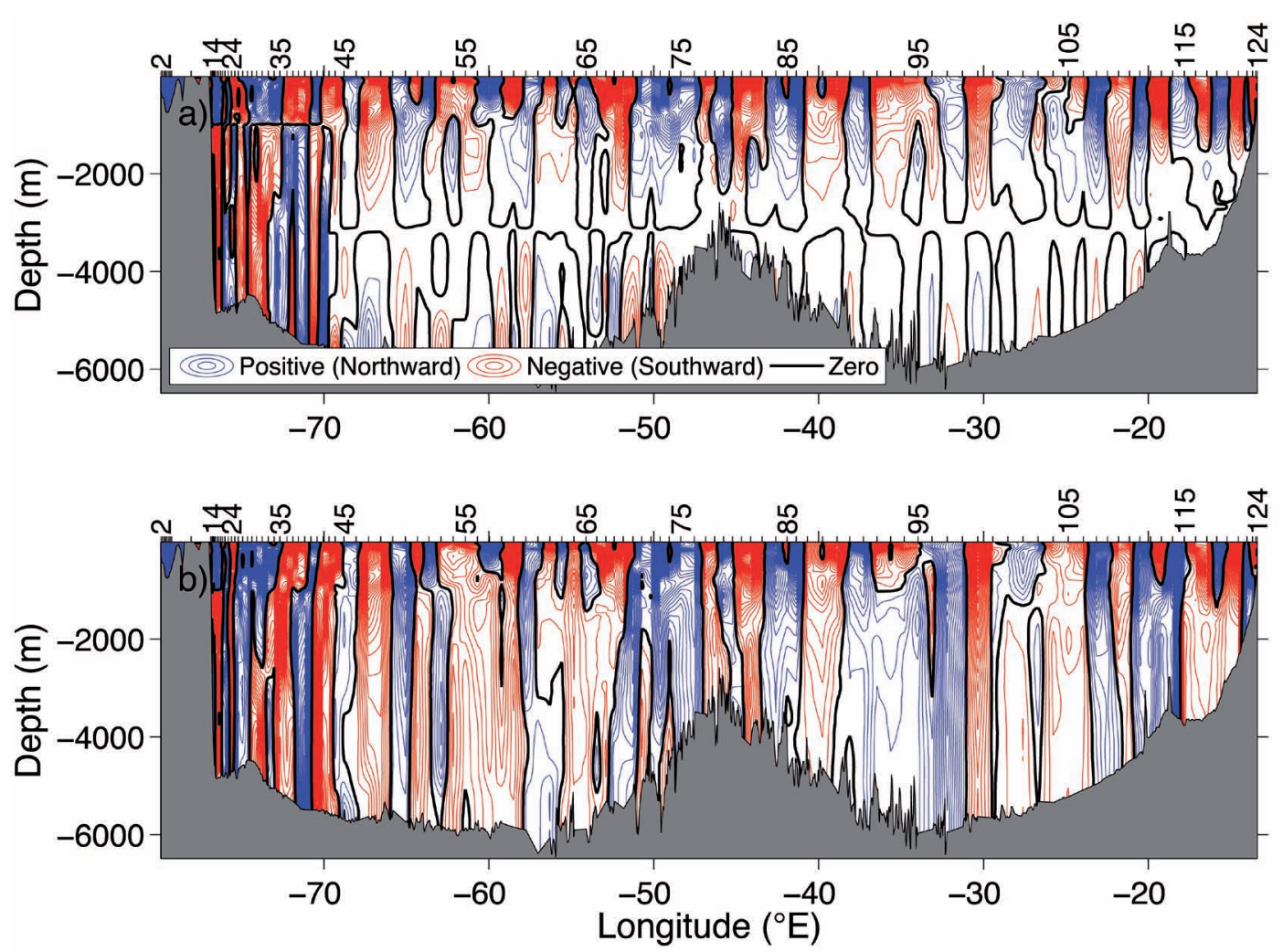

FIG. 7. - Velocity fields $\left(\mathrm{cm} \mathrm{s}^{-1}\right)$ contoured a) before and b) after the correction that applied ADCP referencing. 


\section{DISCUSSION}

Calculating a reference velocity using bottom track LADCP data from cruise D279 along $24.5^{\circ} \mathrm{N}$ has been described. The results indicate that this methodology is useful for obtaining absolute geostrophic estimations from direct velocity observations during the hydrographic measurements. The choice of different initial zero velocity reference levels in the geostrophic calculations modifies the reference velocity obtained in order to apply the correction shown in this work. However, the LADCPreferenced velocity field is the same regardless of this choice, because the LADCP data to which the initial field is referenced is the same.

The most significant advance made in relation to previous works concerning the D279 cruise data is the statistical analysis carried out in order to determine which instrument performed best. The final results were not masked by constraints in the LADCP data processing or the conditioning of the performance of the different devices .

These data will be used further by the Ocean Observation and Climate team at the National Oceanography Centre, Southampton (NOCS) to study the Atlantic Meridional Overturning Circulation (AMOC) quantification and dynamics.

In conclusion, the ADCP is a valuable tool for measuring ocean deep velocity profiles. In this study we demonstrate its usefulness for correcting standard hydrographic measurements and calculations. LADCP data processing can provide independent constraints in the study of ocean dynamics through inverse methods. There are still some deficiencies in the resulting data but continuous improvements are being made in the performance of the instruments, as well as their processing and further applications.

\section{ACKNOWLEDGEMENTS}

This work was developed in the National Oceanography Centre, Southampton (NOCS). The first author would like to thank both this institution and its Ocean Observation and Climate research group for their welcome and help during her visit. The chance to carry out this work in the framework of their current research line is highly appreciated. They also provided the cruise D279 data, which was supported by the Natural and Environmental Research Council (NERC) as part of the Core Strategic Research Programme 'Ocean Variability and Climate' at NOCS. Special thanks to Dr. Brian King for his assistance and support. The first author was also granted a fellowship by the Spanish 'Ministerio de Ciencia e Innovación' during the development of her $\mathrm{PhD}$ thesis. This study has been partly funded by the MOC project (CTM 2008-06438), financed by the Spanish Government and Feder.

\section{REFERENCES}

Baringer, M.O. and R. Molinari. - 1999. Atlantic Ocean baroclinic heat flux at 24 to $26^{\circ}$ N. Geophys. Res. Lett., 26: 353-356.

Beal, L.M. and H.L. Bryden. - 1997. Observations of an Agulhas Undercurrent. Deep-Sea Res., 44: 1715-1724.

Bryden, H.L., H.R. Longworth and S.A. Cunningham. - 2005. Slowing of the Atlantic meridional overturning circulation at $25^{\circ}$ N. Nature, 438 : 655-657.

Cunningham, S.A. - 2005. RRS Discovery Cruise D279, 04 Apr - 10 May 2004. A Transatlantic hydrographic section at $24.5^{\circ} \mathrm{N}$. Southampton Oceanography Centre Cruise Report, No. 54, 198 pp.

Cunningham, S.A, T. Kanzow, D. Rayner, M.O. Baringer, W.E. Johns, J. Marotzke, H.R. Longworth, E.M. Grant, J.J.M. Hirschi, L.M. Beal, C.S. Meinen and H.L. Bryden. - 2007. Temporal variability of the Atlantic meridional overturning circulation at $26^{\circ}$ N. Science, $317: 935-938$.

Egbert, G.D., A.F. Bennett and M.G.G. Foreman. - 1994. TOPEX/ POSEIDON tides estimated using a global inverse model, $J$. Geophys. Res., 99(C12): 24,821-24,852.

Egbert, G.D. and S.Y. Erofeeva. - 2002. Eficient Inverse Modeling of Barotropic Ocean Tides. J. Atmos. Ocean. Tech., 19: 183-204.

Fischer, J. and M. Visbeck. - 1993. Deep Velocity Profiling with Self-contained ADCPs. J. Atmos. Ocean. Tech., 10: 764-773.

Fuglister, F.C. - 1960. Atlantic Ocean Atlas of Temperature and Salinity Profiles and Data from the International Geophysical Year of 1957-1958. Woods Hole Oceanographic Institution Atlas Series, 1: 1-209.

Joyce, T. M., A. Hernández-Guerra and W. M. Smethie Jr. - 2001. Zonal circulation in the NW Atlantic and Caribbean from a meridional World Ocean Circulation Experiment hydrographic section at $66^{\circ}$ W. J. Geophys. Res., 106(C10): 22,095-22,113.

Kanzow, T., S.A. Cunningham, D. Rayner, J.J.M Hirschi, W.E. Johns, M.O. Baringer, H.L. Bryden, L.M. Beal, C.S. Meinen and J. Marotzke. - 2007. Observed flow compensation associated with the MOC at $26.5^{\circ} \mathrm{N}$ in the Atlantic. Science, 317: 938-941.

McDonagh, E.L., H.L. Bryden, B.A. King and R.J. Sanders - 2008. The circulation of the Indian Ocean at $32^{\circ}$ S. Prog. Oceanogr., 79: 20-36.

Parrilla, G., A. Lavín, H. Bryden, M. García and R. Millard. - 1994. Rising temperatures in the subtropical North Atlantic Ocean over the past 35 years. Nature, 369: 48-51.

Roemmich, D. and C. Wunsch. - 1985. Two transatlantic sections: meridional circulation and heat flux in the subtropical North Atlantic Ocean. Deep-Sea Res., 32: 619-664.

Visbeck, M. - 2002. Deep Velocity Using Lowered Acoustic Doppler Current Profilers: Bottom Track and Inverse Solutions. J. Atmos. Ocean. Tech., 19: 794-807.

Scient. ed.: J. Font.

Received June 3, 2009. Accepted September 16, 2009.

Published online March 8, 2010. 